\title{
Development and Collaborative Study of a Diluted Acid Mild Extraction Method for Determination of Cadmium in Grain by Graphite Furnace Atomic Absorption Spectrometry
}

\author{
Minghui Zhou,* Yanxiang Wu,* Jieqiong Zhang, ${ }^{*}$ Yan Zhang, ${ }^{* *}$ Xi Chen, ${ }^{*}$ Jin Ye,* and \\ Songxue WANG*广
}

*The Academy of National Food and Strategic Reserves Administration (Former name: Academy of State

Administration of Grain, ab. ASAG), No. 11 Baiwanzhuang Str, Xicheng District, Beijing 100037, China

**Standards and Quality Center of State Administration of Grain, No. 11 Baiwanzhuang Str, Xicheng District, Beijing, China

\begin{abstract}
The traditional pretreatment methods for the determination of cadmium in grain are time-consuming, cost-consuming, and unfriendly to human health and the environment. To eliminate these disadvantages, we developed an accurate, time-, energy- and cost-efficient method for determination of $\mathrm{Cd}$ in grain coupled with graphite furnace atomic absorption spectrometry (GFAAS). The optimization conditions of the extraction were achieved, the accuracy was verified and a collaborative study was organized to evaluate the methods. The detection limit and quantification limit were 0.016 and $0.048 \mu \mathrm{g} \mathrm{L}^{-1}$, respectively. The whole pretreatment time was reduced to $15 \mathrm{~min}$, and there was no significant difference $(P>0.05)$ between the extraction method and the classic pretreatment method. The method proved to be highly consistent with the results of laboratories in different countries, as determined from two international proficiency tests $(|Z| \leq 0.3)$. The repeatability, reproducibility, and HorRat values of the collaborative results were $2.7-4.9 \%, 9.4-11.7 \%$, and $0.42-0.58$, respectively. The method of diluted acid mild extraction coupled with GFAAS is efficient, cost-saving, convenient and friendly.
\end{abstract}

Keywords Diluted acid mild extraction, graphite furnace atomic absorption spectrophotometer, grain, Cd

(Received July 17, 2018; Accepted October 23, 2018; Advance Publication Released Online by J-STAGE November 2, 2018)

\section{Introduction}

Cadmium (Cd) is known as a hazardous environmental pollutant that can have toxic effects on human body and organs. The International Agency for Research on Cancer (IARC) classifies Cd and cadmium compounds as Group I agents of carcinogens for the human body. ${ }^{1,2}$ In addition, many research studies have demonstrated that $\mathrm{Cd}$ is likely to accumulate in human bone, eyes and other organs or tissues, especially kidney and bone, ${ }^{3,4}$ which can cause renal failure, broken bones and other diseases..$^{5-7}$ Recently, there have been reports of Cd contamination of grain, which has stirred up public interest. It is thus very important to detect $\mathrm{Cd}$ in grain quickly and accurately.

Current, detection methods for $\mathrm{Cd}$ in grain mainly included GFAAS, inductively coupled plasma mass spectrometry (ICP-MS), and inductively coupled plasma atomic emission spectrometry (ICP-OES), ${ }^{8-14}$ which are quick and accurate. However, the pretreatment methods, such as the wet digestion, dry ashing and microwave digestion, ${ }^{15-19}$ still require a large volume of nitric acid (grade pure), strong oxidizer, and high temperature or pressure. Compared with the efficiency of instrument detection, the pretreatment methods take $2-5 \mathrm{~h}$ and

$\dagger$ To whom correspondence should be addressed.

E-mail:wsx@chinagrain.org are thus time-consuming. The traditional pretreatment methods are time-, agent- and energy-consuming, and unfriendly to experimenters and the environment.

Some heavy metals can be extracted efficiently by acid solution, but the pretreatment procedures are complex and the total time required is still not short for the efficient determination of a large volume of grain samples, ${ }^{20-23}$ In view of this situation, this paper presented a rapid pretreatment method-diluted acid mild extraction for determining $\mathrm{Cd}$ in grain via the optimization of the conditions for extraction. The method is efficient, costsaving and convenient, and can determine $\mathrm{Cd}$ in grain within 15 min accurately. Furthermore, the method should contribute to improving the capacity of governments, institutions, and third-party companies for Cd detection.

\section{Experimental}

\section{Reagents and materials}

The samples (brown rice powder, wheat powder and maize powder) containing $\mathrm{Cd}$ were provided by the Academy of State Administration of Grain, CRMs (certified reference materials) of IRMM-804 (rice flour), NIST 1568b (rice flour), GBW08503c (wheat flour) and GBW(E)100380 (maize flour) were used for the extraction method.

Nitric acid $\left(\mathrm{HNO}_{3}, \mathrm{GR}\right)$, hydrogen peroxide $\left(\mathrm{H}_{2} \mathrm{O}_{2}, \mathrm{GR}\right)$, and 
high purity argon (99.999\%) were used. All aqueous solutions were prepared with ultra-pure water obtained from a Milli-Q purification system, and the analytical reference solutions of $\mathrm{Cd}$ were prepared successively diluting the $1000 \mathrm{mg} \mathrm{kg}^{-1} \mathrm{Cd}$ standard stock solution with $0.5 \%\left(\mathrm{v} \mathrm{v}^{-1}\right)$ nitric acid solution to different concentrations.

First, $0.5 \%$ nitric acid solution $\left(\mathrm{v} \mathrm{v}^{-1}\right)$ was prepared by adding $0.5 \mathrm{~mL} \mathrm{HNO}_{3}(\mathrm{GR})$ in a $100-\mathrm{mL}$ volumetric flask, diluting with ultra-pure water and putting it in a Teflon PFA bottle. The other concentration of nitric acid solutions were the same.

\section{Instruments and conditions}

Instruments used included a sieve, with aperture sizes of $0.250,0.380$, and $0.550 \mathrm{~mm}$, analytical balance (accurate to $1 \mathrm{mg}$ ), centrifuge (with positions for $10 \mathrm{~mL}$ centrifuge tubes and $3000 \mathrm{rpm}$ of speed), grinding mill, the particle size was 60 meshes $(0.250 \mathrm{~mm})$, and microwave digestion system.

An atomic absorption spectrometer (Analytik Jena, ZEEnit $700 \mathrm{P}$, Germany), equipped with graphite furnace and Cd hollow cathode lamp, was used for the measurements. Cd hollow cathode lamp with wavelength $228.8 \mathrm{~nm}$ was employed as a radiation source throughout the measurement. Slit width was $0.8 \mathrm{~nm}$, lamp current was $4 \mathrm{~mA}$, Zeeman correction was used for background correcting, pyrolysis temperature was $350^{\circ} \mathrm{C}$, and atomization temperature was $1200^{\circ} \mathrm{C}$.

ICP-MS (Agilent, 7500CX, USA) electrospray ionization source was operated under no gas mode, the optimum parameters were set at RF power of $1500 \mathrm{~W}$, Torch- $\mathrm{H}$ of $-0.3 \mathrm{~mm}$, Torch-V of $-0.4 \mathrm{~mm}$, carrier gas flow rate of $0.76 \mathrm{~L} \mathrm{~min}^{-1}$, makeup gas flow rate of $0.45 \mathrm{~L} \mathrm{~min}^{-1}$, sampling depth of $8.0 \mathrm{~mm}$, nebulizer pump flow rate of $0.10 \mathrm{rps}$, integration time of $0.3 \mathrm{~s} \mathrm{point}^{-1}$, and sampling mass: ${ }^{111} \mathrm{Cd}$.

\section{Sample preparation}

The certain mesh of sample was prepared by adding more than $500 \mathrm{~g}$ sample into the grinding mill until it all passed through the sieve and then mixed thoroughly.

Samples for GFAAS and ICP-MS determination with microwave digestion were prepared as follows: $0.2-0.3 \mathrm{~g}$ of milled and thoroughly homogenized samples were digested with $5 \mathrm{~mL} \mathrm{HNO}_{3}$ and $2 \mathrm{~mL} \mathrm{H}_{2} \mathrm{O}_{2}$ using microwave digestion system. After that, the samples were heated to near dryness and diluted with high purity water, and the solutions were transferred to a vial and fixed to $10-25 \mathrm{~mL}$.

Samples for GFAAS determination with extraction were prepared as follows: $0.2 \mathrm{~g}$ of milled and thoroughly homogenized samples were weighed, and $5 \mathrm{~mL}$ of extraction solution was added. After extraction progress, the extraction solution was obtained.

Sediments of the grain extractions were all transferred to the digestion tube, digested with $7 \mathrm{~mL} \mathrm{HNO}_{3}$ solution, and fixed to $10-25 \mathrm{~mL}$ with ultrapure water.

\section{Validation of analytical method}

The developed analytical method was validated for limit of detection (LOD), limit of quantitation (LOQ), accuracy and collaborative study.

\section{Limit of detection and quantification}

LOD and LOQ were calculated as the ratio of 3 and 10-fold of the standard deviation of the absorption of 11 blanks to the slope of the standards calibration curve, respectively.

\section{Accuracy of method}

The accuracy was assessed via comparison of different

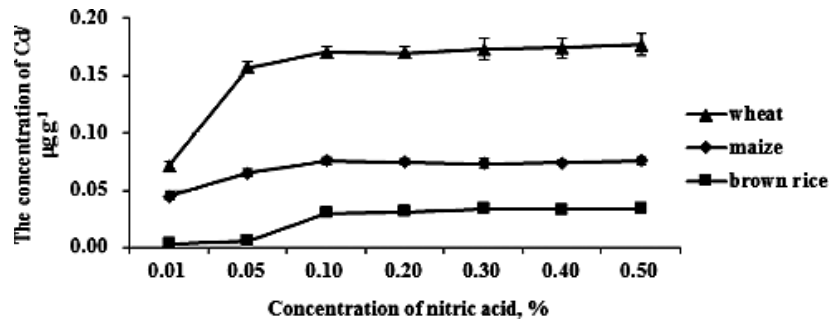

Fig. 1 Effects of different nitric acid concentrations.

methods and participation in the Cd in Powder Rice Test (Test No. 07273) of the Food Analysis Performance Assessment Scheme (FAPAS, 2014) and in the Cd in Powder Rice Test (Test No. 07279) of the Food Analysis Performance Assessment Scheme (FAPAS, 2016).

\section{Collaborative study}

The precision of this method was achieved in terms of repeatability and reproducibility from a collaborative study. Seven naturally contaminated samples (three levels of brown rice, three levels of wheat, and one level of maize) were selected in this collaborative study. The naturally contaminated samples, which had been checked for homogeneity and were found to be sufficiently homogeneous and stable according to the criteria of the International Union of Pure and Applied Chemistry's (IUPAC) International Harmonized Protocol, ${ }^{24}$ contained different concentrations of $\mathrm{Cd}$. These three representative grain matrices were selected as they were prone to $\mathrm{Cd}$ contamination. Each sample was packed in hermetically sealed resistant bags and blindly labeled with identification information and serial number.

Fifteen laboratories from China participated in the collaborative trial. The participants were asked to strictly follow the protocol of the method.

The statistical analysis of the results, namely the detection and elimination of outliers, evaluation of precision parameters (repeatability and reproducibility), and means and HorRat values were based on the standard ISO $5725-2 .{ }^{25}$

\section{Results and Discussion}

\section{Optimization of sample pretreatment}

To make sure $\mathrm{Cd}$ in the grain samples was extracted thoroughly, it was necessary to optimize the extraction concentration, the setting mode and time, extraction time, the grain diameter and the ratio of liquid and solid. To ensure thorough extraction of the $\mathrm{Cd}$ in three matrices, an nitric acid concentration of $0.5 \%$ (Fig. 1), a setting time of $10 \mathrm{~min}$ and diameter less than $0.550 \mathrm{~mm}$ of the samples were adopted, the results also shown that the sufficient shake without any else extraction time and the ratio of liquid and solid between 2:50 and 5:50 was good enough for $\mathrm{Cd}$ in the grain fully extracted .

This method was faster, simpler and more efficient than that of extracting $\mathrm{Pb}$ from grain. For $\mathrm{Pb}$, at least 15 min were need for extraction, the chemical modifier and matrix matching standard curve were necessary for the matrix effect and the extraction efficiency was only between $91.6-94.6 \% .^{20}$

Method validation

Calibration curves, linearity, and limit of detection and quantification. The calibration curve was shown in Fig. 2, and 
$R^{2}$ of the curve was 0.9996 . The LOD and LOQ were calculated by Cd blank samples. From the results shown in Table 1, the LOD and LOQ of this method were below the classic method, fully meeting the demand for determination of the international those of $\mathrm{Cd}$ in grain.

Accuracy of method. In order to ensure the accuracy of the extraction method, a comparison of the established method and the classical method was studied. The $\mathrm{Cd}$ contents in brown rice, wheat and maize were determined by GFAAS with microwave digestion, ICP-MS with microwave and GFAAS with nitric acid extraction, respectively. There were no

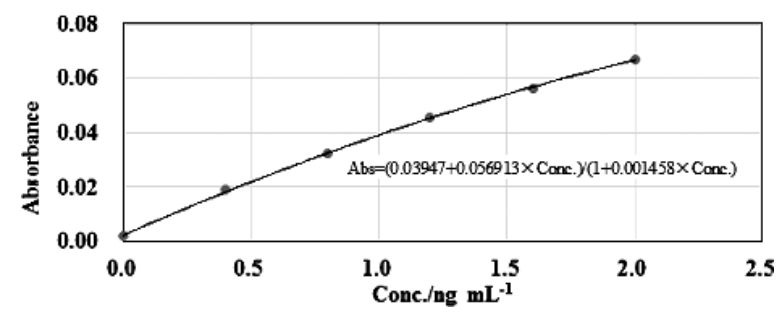

Fig. 2 The standards curve of Cd.

Table 1 LOD and LOQ of extraction method and microwave digestion

\begin{tabular}{ccc}
\hline Sample & Diluted nitric acid extraction & Microwave digestion \\
\hline $\mathrm{LOD} / \mu \mathrm{g} \mathrm{L}^{-1}$ & 0.0253 & 0.0388 \\
$\mathrm{LOQ} / \mu \mathrm{g} \mathrm{L}^{-1}$ & 0.0843 & 0.1268 \\
\hline
\end{tabular}

Table 2 Detection results of different methods

\begin{tabular}{lcccc}
\hline \multirow{2}{*}{ Sample } & $\begin{array}{c}\text { Diluted acid } \\
\text { extraction }\end{array}$ & $\begin{array}{c}\text { Microwave } \\
\text { digestion }\end{array}$ & & \multirow{2}{*}{$\begin{array}{c}\text { Microwave } \\
\text { digestion }\end{array}$} \\
\cline { 2 - 3 } & \multicolumn{2}{c}{ GFAAS/mg kg-1 } & & ICP-MS/mg kg-1 \\
\hline Maize & $0.0702 \pm 0.0051$ & $0.0705 \pm 0.0051$ & & $0.0719 \pm 0.0041$ \\
Wheat & $0.172 \pm 0.003$ & $0.170 \pm 0.011$ & & $0.171 \pm 0.007$ \\
Brown rice & $0.0336 \pm 0.0002$ & $0.0332 \pm 0.0023$ & $0.0347 \pm 0.0024$ \\
\hline
\end{tabular}

significance differences $(P>0.05)$ among them (Table 2$)$. The results suggested GFAAS with the extraction method was reliable for determining $\mathrm{Cd}$ in grain.

Furthermore, the accuracy of the method was also verified via participation in two proficiency tests (PT). Rice was used as the sample for FAPAS (Test Nos. 07219 and 07273). The results were summarized in Table 3 . The absolute values of $Z$-scores of this method were no more than 0.3 . The result of the extraction method was remarkably consistent with the other laboratories from different countries using different pretreatment and determination methods.

Collaborative study. Fifteen laboratories from China participated in this study. All participants submitted the results before the deadline.

The results of the collaborative study were analyzed according to ISO 5725-2. Cochran and Grubbs' tests were used to remove outliers. Table 4 shows the statistical results obtained for the studied analytes. The relative standard deviation of repeatability (RSDr) was in the range $2.7-4.9 \%$ and the relative standard

Table 3 Results, assigned value and $Z$-score of proficiency

\begin{tabular}{|c|c|c|c|}
\hline & Proficiency test & $\begin{array}{c}2014 \\
\text { FAPAS } \\
\text { (Test } \\
07219 \text { ) }\end{array}$ & $\begin{array}{c}2016 \\
\text { FAPAS } \\
(\text { Test } \\
07273 \text { ) }\end{array}$ \\
\hline \multirow{8}{*}{$\begin{array}{l}\text { Laboratory } \\
\text { number of } \\
\text { using different } \\
\text { pretreatment } \\
\text { method }\end{array}$} & Dry ashing & 5 & 8 \\
\hline & High pressure asher & 5 & 5 \\
\hline & Microwave digestion & 52 & 57 \\
\hline & Pressure bomb digestion & 2 & 1 \\
\hline & Solvent extraction & 1 & 2 \\
\hline & Wet digestion & 8 & 12 \\
\hline & Block digestion & - & 1 \\
\hline & Wet digestion in closed vessel & - & 1 \\
\hline \multirow{7}{*}{$\begin{array}{l}\text { Laboratory } \\
\text { number of } \\
\text { using different } \\
\text { determination } \\
\text { method }\end{array}$} & $\begin{array}{l}\text { Cold vapor/hydride generation } \\
\text { AAS }\end{array}$ & 1 & 3 \\
\hline & Flame AAS & 3 & 4 \\
\hline & Graphite furnace AAS & 19 & 20 \\
\hline & Hydride generation ICP-MS & 1 & 1 \\
\hline & ICP-MS & 47 & 55 \\
\hline & ICP-OES/AES & 2 & 4 \\
\hline & ICP & & 1 \\
\hline \multicolumn{2}{|c|}{ Assigned value/mg kg-1 } & 0.03005 & 0.0474 \\
\hline \multicolumn{2}{|c|}{ Result/mg kg-1 } & 0.0286 & 0.0502 \\
\hline \multicolumn{2}{|l|}{$Z$-score } & 0.2 & -0.3 \\
\hline
\end{tabular}

Table 4 Statistical analysis of collaborative study results

\begin{tabular}{|c|c|c|c|c|c|c|c|}
\hline \multirow{2}{*}{ Sample } & \multirow{2}{*}{$\begin{array}{c}\text { Naturally } \\
\text { contaminated } \\
\text { maize }\end{array}$} & \multicolumn{3}{|c|}{ Naturally contaminated wheat } & \multicolumn{3}{|c|}{ Naturally contaminated rice } \\
\hline & & Level 3 & Level 2 & Level 1 & Level 3 & Level 2 & Level 1 \\
\hline Number of laboratories & 15 & 15 & 15 & 15 & 15 & 15 & 15 \\
\hline Number of samples & 2 & 2 & 2 & 2 & 2 & 2 & 2 \\
\hline Number of laboratories retained after eliminating outliers & 13 & 12 & 15 & 12 & 13 & 14 & 15 \\
\hline Number of outliers (laboratories) & 2 & 3 & 0 & 3 & 2 & 1 & 0 \\
\hline Number of accepted results & 26 & 24 & 30 & 24 & 26 & 28 & 30 \\
\hline Mean value $x / \mathrm{mg} \mathrm{kg}^{-1}$ & 0.037 & 0.18 & 0.13 & 0.062 & 0.42 & 0.22 & 0.16 \\
\hline Repeatability standard deviation $s_{\mathrm{r}} / \mathrm{mg} \mathrm{kg}^{-1}$ & 0.0013 & 0.0070 & 0.0064 & 0.0028 & 0.011 & 0.0092 & 0.0060 \\
\hline Repeatability relative standard deviation $\mathrm{RSDr}$ & $3.5 \%$ & $3.9 \%$ & $4.9 \%$ & $4.5 \%$ & $2.7 \%$ & $4.2 \%$ & $3.9 \%$ \\
\hline Repeatability limit $r / \mathrm{mg} \mathrm{kg}^{-1}$ & 0.0036 & 0.020 & 0.018 & 0.0080 & 0.032 & 0.026 & 0.017 \\
\hline Reproducibility standard deviation $s_{\mathrm{R}} / \mathrm{mg} \mathrm{kg}^{-1}$ & 0.0042 & 0.0209 & 0.0145 & 0.0062 & 0.041 & 0.026 & 0.015 \\
\hline Reproducibility relative standard deviation $\mathrm{RSD}_{\mathrm{R}}$ & $11.4 \%$ & $11.7 \%$ & $11.2 \%$ & $10.0 \%$ & $9.7 \%$ & $11.6 \%$ & $9.4 \%$ \\
\hline Reproducibility limit $R / \mathrm{mg} \mathrm{kg}^{-1}$ & 0.012 & 0.059 & 0.041 & 0.018 & 0.11 & 0.073 & 0.041 \\
\hline HorRat value & 0.44 & 0.57 & 0.52 & 0.42 & 0.54 & 0.58 & 0.45 \\
\hline
\end{tabular}


Table 5 Results of the verification for extraction mechanism $(n=4)$

\begin{tabular}{lcccc}
\hline \multicolumn{1}{c}{ CRMs } & IRMM804 & NIST 1568b & GBW08503c & GBW(E) 100380 \\
\hline Cd content in sediment/mg kg-1 & $0.024 \pm 0.014$ & ND & ND & ND \\
Cd content in the extraction/mg kg-1 & $1.586 \pm 0.047$ & $0.023 \pm 0.002$ & $0.211 \pm 0.012$ & $0.045 \pm 0.004$ \\
Certified value $/ \mathrm{mg} \mathrm{kg}^{-1}$ & $1.61 \pm 0.07$ & $0.0224 \pm 0.0013$ & $0.211 \pm 0.014$ & $0.045 \pm 0.004$ \\
Cd extraction rate, $\%$ & 98.5 & 101.7 & 100.1 & 100.0 \\
\hline
\end{tabular}

deviation of reproducibility $\left(\mathrm{RSD}_{\mathrm{R}}\right)$ was in the range $9.4-11.7 \%$. To evaluate the acceptability of precision of this method, HorRat values were calculated by comparing the $\mathrm{RSD}_{\mathrm{R}}$ with the respective predicted value at specific sample concentrations according to the Horwitz. ${ }^{26}$ HorRat values of this method ranged from $0.42-0.58$. All HorRat values were $<2.0$, which is indicative of acceptable reproducibility precision. All the performance characteristics of the method developed in this study, such as recovery, repeatability and reproducibility, were adequately compliant with the performance criteria of EU. ${ }^{27}$ The results of the collaborative study demonstrate that the method is suitable for detecting Cadmium in cereals.

\section{Extraction mechanism discussion}

Plants have a mechanism to deal with levels of toxic heavy metals to resist the damage via metal-binding protein. ${ }^{28,29}$ The Cd-binding protein in grains was used to decrease the stress from $\mathrm{Cd}$ in the environment. ${ }^{30}$ This kind of protein from grains accounts for only a small fraction of total protein, among which the metallothionein (MT) play an important role. When the $\mathrm{Cd}^{2+}$ is transferred into the plant cell, $\mathrm{Cd}^{2+}$ will replace $\mathrm{Cu}^{2+}$ and $\mathrm{Zn}^{2+}$ by binding to MT to achieve the toxicity attenuation, ${ }^{31}$ and the Cd-MT will lose $\mathrm{Cd}^{2+}$ and form apo-MT in acidic conditions. When the $\mathrm{pH}<3$, the $\mathrm{Cd}^{2+}$ will be released completely, ${ }^{32}$ this is a mechanism allowing for use of the diluted nitric acid to extract cadmium from grain. Other Cd-binding forms reported also were not stable in acidic conditions, ${ }^{33-35}$ so we speculated that cadmium in grains could be extracted by diluted acid. For further verification of the possibility, the Cd contents of the extraction solution and sediment were analyzed by the highly sensitive ICP-MS method (Table 5). The Cd contents detected in the extraction solutions were in good agreement with the assigned value. Cd extraction rate was between $98.5-101.7 \%$, the $\mathrm{Cd}$ contents that remained in the sediment could be ignored.

\section{Conclusions}

We successfully developed and optimized a pretreatment method for $\mathrm{Cd}$ in cereals using diluted acid extraction coupled with GFAAS. Method validation results showed that the method provided good linear relation, precision, LODs, LOQs and recoveries. The method was also verified via participation in two proficiency tests. Compared to the classic pretreatment method, the extraction method needs less pretreatment time, reagents and experimental instruments. Furthermore, the results of the collaborative study demonstrated that this approach could meet the requirements of a rapid, reliable, and efficient method for the detection of $\mathrm{Cd}$ in grain at concentrations of regulatory significance with satisfactory accuracy and precision.

\section{Acknowledgements}

This work was conducted at the Academy of State Administration of Grain and was supported by the research project of public welfare grain industry (Grant No. 201513006).

\section{References}

1. P. Hotz, J. P. Buchet, A. Bernard, D. Lison, and R. Lauwervs, Lancet, 1999, 354, 1508.

2. Joint FAO/WHO Expert Committee on Food Additives, 2010, Seventy-third Meeting Geneva, 8 - 17.

3. Y. F. Shao, Y. Chen, J. Liu, P. P. Wu, Y. B. Ying, and J. Xie, Food Anal. Method, 2016, 9, 3501.

4. C. Blake and B. Bourqui, Atom. Spectrosc., 1998, 19, 207.

5. K. Khan, H. Khan, Y. Lu, I. Ihsanullah, J. Nawab, S. Khan, N. S. Shan, I. Shamshad, and A. Maryam, Ecotox. Environ. Safe., 2014, 108, 224.

6. M. Rodríguez-Barranco, M. Lacasaña, F. Gil, A. Lorca, J. Alguacil, D. S. Rohlman, B. González-Alzaga, I. MolinaVillalba, R. Mendoza, and C. Aquilar-Garduño, Environ. Res., 2014, 134, 66.

7. G. M. A. Bermudez, R. Jasan, T. Černohorsky, and J. Zelenková, J. Hazard. Mater., 2011, 193, 264.

8. N. A. Aristidis, C. Mitani, P. Balkatzopoulou, P. D. Tzanavaras, Anal. Chim. Acta, 2012, 733, 34.

9. M. Uemoto, M. Markion, Y. Ota, H. Sakaguchi, Y. Shimizu, and K. Sato, Anal. Sci., 2018, 34, 719.

10. X. Q. Guo, M. He, B. B. Chen, and B. Hu, Talanta, 2012, $101,516$.

11. Y. Fang, X. Y. Sun, W. J. Yang, N. Ma, Z. H. Xin, J. Fu, X. C. Liu, A. M. Mariga, X. F. Zhu, and Q. H. Hu, Food Chem., 2014, 147, 147.

12. L. Bendakovská, A. Krejčová, T. Černohorsky, and J. Zelenková, Chem. Papers, 2016, 70, 1155.

13. C. Voica, A. Dehelean, and M. H. Kovacs, AIP Conference Proceedings, 2012, 1425, 110.

14. D. G. Silva, M. M. S. Junior, L. O. B. Silva, L. A. Portugal, G. D. Matos, and S. L. C. Ferreira, Anal. Methods, 2011, 3, 2495.

15. EN 14082:2003, "Foodstuffs Determination of Trace Elements, Determination of Lead, Cadmium, Zinc, Copper, Iron and Chromium by Atomic Absorption Spectrometry (AAS) after Dry Ashing".

16. EN 14083:2003, "Foodstuffs Determination of Trace Elements Determination of Lead, Cadmium, Chromium and Molybdenum by Graphite Furnace Atomic Absorption Spectrometry (GFAAS) after Pressure Digestion”.

17. EN 14084:2003, "Foodstuffs Determination of Trace Elements Determination of Lead, Cadmium, Zinc, Copper and Iron by Atomic Absorption Spectrometry (AAS) after Microwave Digestion".

18. AOAC Official Method 999.10, "Lead, Cadmium, Zinc, Copper, and Iron in Foods Atomic Absorption Sepctrophotometry after Microwave Digestion", 2011, AOAC International, Gaithersburg, MD.

19. EN ISO 15774-2012, “Animal and Vegetable Fats and Oils. 
Determination of Cadmium Content by Direct Graphite Furnace Atomic Absorption Spectrometry".

20. M. H. Zhou, S. X. Wang, and Y. X. Wu, Chin. J. Anal. Chem., 2014, 42, 459.

21. K. Abe, K. Nakamura, T. Arao, Y. Sakurai, A. Nakano, C. Suginuma, and K. Tawarada, J. Sci. Food Agr., 2011, 91, 1392.

22. T. Kikuchi, M. Okazaki, S. D. Kimura, T. Motobayashi, J. Baasansuren, T. Hattori, and T. Abe, J. Hazard. Mater, 2008, 154, 294.

23. S. C. Nunez, J. Benning, C. Liu, P. Branton, J.Hu, K. G. McAdam, S. Coburn, J. Braybrook, and H. G. Infrante, Anal. Bioanal. Chem., 2018, 410, 6795.

24. M. Thompson, S. L. R. Ellison, and R. Wood, Pure Appl. Chem., 2006, 78, 145.

25. ISO5725-2:1994, “Accuracy (Trueness and Precision) of Measurement Methods and Results-Part 2: Basic Method for the Determination of Repeatability and Reproducibility of a Standard Measurement Method".

26. The Commission of the European Communities, Commission Regulation (EC) No. 401/2006 of 23 February 2006 Laying Down the Methods of Sampling and Analysis for the Official Control of the Levels of Mycotoxins in Foodstuffs.

27. L. V. Kochian, N. S. Pence, and D. L. D. Letham, Plant Soil., 2002, 247, 109.

28. M. Seneviratne, M. Seneviratne, N. Rajakaruna, M. Rizwan, H. M. S. P. Madawala, Y. S. Ok, and M. Vithanage, Environ. Geochem. Hlth., 2017, 1,19.

29. C. H. Kao, Environ. Bioinformatics, 2017, 14, 1.

30. S. Wei, B. Guo, L. X. Feng, T. Jiang, M. Li, and Y. Wei, Food Sci. Technol. Res., 2017, 23, 661.

31. H. Mao, D. H. Wang, and W. X. Yang, Aquat. Toxicol., 2012, 110, 208.

32. T. Q. Wang, Expression, Purification and Spectroscopic Characterization of a Particular Plant Metallothionein: Maize MT1, 2016.

33. X. X. Yu, S. Wei, Y. X. Yang, Z. D. Ding, Q. Wang, J. T. Zhao, X. Q. Liu, X. Y. Chu, J. Tian, N. F. Wu, and Y. L. Fan, Int. J. Biol. Macromolecules, 2018, 119, 597.

34. K. T. Suzukia, C. Sasakuraa, and M. Ohmichi, J. Trace Elem. Med. Biol., 1997, 11, 71.

35. W. Horwitz and R. Albert, J. AOAC Int., 2006, 89, 1095. 